\title{
Physicochemical characteristics and antioxidant capacities of peach fruits in the development stages
}

\author{
Chang-Seob Kim ${ }^{1}$, Suk-Hee Lee ${ }^{2}$, Shin-Kyo Chung ${ }^{3 *}$ \\ ${ }^{1}$ Department of Hotel Institute Culinary Art and Bakery, Pohang University, Pohang 37555, Korea \\ ${ }^{2}$ Gyeongsangbuk-do Agricultural Research and Extension Services, Daegu 41404, Korea \\ ${ }^{3}$ School of Food Science and Biotechnology, Kyungpook National University, Daegu 41566, Korea
}

성숙 시기별 복숭아 과일의 이화학적 특성과 항산화능

\author{
김창섭 ${ }^{1} \cdot$ 이숙희 ${ }^{2} \cdot$ 정신교 ${ }^{3 *}$ \\ ${ }^{1}$ 포항대학교 호텔외식조리제빵과, ${ }^{2}$ 경상북도 농업기술원, ${ }^{3}$ 경북대학교 식품공학부
}

\begin{abstract}
In order to promote the utilization of peach fruits, we investigated the physicochemical characteristics of three different varieties of peach, namely, Wild Peach, Hikawa Hakuho, and Baekhyang, in various development stages (stone-hardening, fruit enlargement, and ripening). The peach fruits increased in length, width, and weight in the development stage. Baekhyang had the highest size among all the varieties in the development stage. The ratio of the length and width was the highest in the stone hardening stage and decreased thereafter. The hardness of the peach fruits decreased, except Wild Peach $(\mathbf{p}<0.05)$. The sugar content in all the varieties increased during the development stage, but the acidity decreased. The ratio of sugar and acidity increased with the progress of the development stage. The total phenolic content (TPC) was the highest in Baekhyang in the stone-hardening stage. All the varieties had the highest TPC in the stone-hardening stage, among all the development stages. No significant difference in the DPPH radical scavenging activity was observed in the fruit enlargement and ripening stage across the different varieties. The length, width, and weight of peach fruits increased, but the hardness decreased in the fruit development stage. The ratio of sugar and acidity increased, but the antioxidant capacity decreased.
\end{abstract}

Key words : peach fruits, weight, hardness, sugar/acidity ratio, antioxidant

\section{서 론}

복숭아는 장미과(Rosaceae) 자두속(Prunus) 복숭아아속 (Amygdalus)에 속하는 온대 낙엽성 과수로 대표적인 여름 과일이다. 복숭아는 국내 과일 생산량 중 감귤, 사과, 포도, 배, 단감에 이어 6 위로 국내 전체 과일 생산량의 $8 \%$ 를 점유 하고 있으며, 2015년 기준으로 현재 우리나라 복숭아 재배 면적은 $16,704 \mathrm{ha}$, 생산량은 237,711 ton이다(1). 복숭아는

*Corresponding author. E-mail : kchung@knu.ac.kr Phone : 82-53-950-5778, Fax : 82-53-950-6772

Received 21 November 2018; Revised 21 December 2018; Accepted 24 December 2018.

Copyright (c) The Korean Society of Food Preservation. All rights reserved. malic acid, tartaric acid, citric acid 등의 유기산이 함유되어 있고, aspartic acid, glutamic acid, serine 등 유리 아미노산의 함량이 높다 $(2,3)$. 복숭아는 재배과정에서 해거리 방지, 착 과량 조절 등의 목적으로 3-4회에 걸쳐 30-40\%의 미숙과의 적과를 실시하는데, 이때 적과된 복숭아는 대부분 활용되 지 못하고 전량 폐기되고 있어, 부가가치 창출 및 가격 안정 화를 위해 적과된 복숭아 유과의 활용이 필요한 실정이다. 사과 미숙과의 경우는 완숙과보다 폴리페놀화합물의 함량 과 항산화 활성이 높아서(4) 기능성 소재로서 주목받고 있 다.

복숭아 유과는 oxalic acid를 비롯한 유기산과 아미노산 이 풍부하며(5), 섭취에 따른 용혈성 빈혈 개선 효과(6), 추출물의 미백 효과(7) 등이 보고되었다. 또한 성숙에 따라 amygdalin 함량(8), 펙틴 성분 및 관련 효소 활성 $(9,10)$, 항산 
화 및 항염증 효과(11) 등이 보고되었다.

최근 식생활을 통한 대사성 질환의 예방과 노화 방지 목적으로 식용식물자원의 생리활성물질과 생체 기능성에 관하여 많은 연구들이 이루어지고 있으며, 이중 폴리페놀 화합물과 생체 항산화 기능성에 관한 연구가 많다.

따라서 본 연구는 복숭아 유과를 고부가가치 기능성 소 재로써 활용 가능성을 제고하기 위하여, 품종별로 성숙 시 기에 따라 이화학적 특성과 항산화능을 조사하여 보고하는 바이다.

\section{재료 및 방법}

\section{실험재료}

실험 재료는 돌복숭아(Wild Peach, Pruns persica L.), 일 천백봉(Hikawa Hakuho, Pruns persica L.), 백향(Baekhyang, Pruns persica L.) 품종을 사용하였으며 2017년 청도 복숭아 시험장에서 품종별로 각각 경핵기(stone hardening stage), 과실비대기(fruit enlargement stage), 성숙기(ripening stage) 에 채취하였다. 경핵기는 6월 중순경 적과 시기에 세 품종 모두 같이 채취하였으며, 과실비대기의 경우 돌복숭아는 8월 상순경, 일천백봉은 7월 상순경, 백향은 7월 하순경에 채취하였다. 성숙기의 경우 돌복숭아는 9월 상순경, 일천백 봉은 7월 하순경, 백향은 8월 하순경에 각각 채취하여 실험 재료로 사용하였다.

\section{이화학적 품질 특성 측정}

성숙 시기별로 경핵기, 과실비대기, 성숙기에 채취한 복
숭아 과일의 과경, 과폭, 과중, 경도, 당도, 산도를 측정하였 다. 과경 및 과폭은 ALLTRADE dial caliper(Long beach, $\mathrm{CA}, \mathrm{USA}$ )로, 과중은 METTLER TOLEDO digital balance (B3002DR, Schwarzenbasch, Switzerland)로 측정하였다. 경 도는 Rheometer(Compac-100, Sun Scientific Co., Tokyo, Japan)로 aluminium cylinder probe를 사용하여 측정하였다. 당도는 굴절당도계(ATAGO-N-1a, Antage, Tokyo, Japan)로 측정하였다. 산도는 $0.1 \mathrm{~N}$ sodium hydroxide로 $\mathrm{pH}$ 8.1까지 의 적정액을 주석산 함량으로 환산하여 총산 함량 $(\%, \mathrm{w} / \mathrm{v})$ 으로 표시하였다(12).

\section{항산화능 측정}

복숭아 과일의 항산화능으로는 총페놀 함량과 DPPH 라 디칼 소거능을 측정하였다. 총페놀 함량은 Hammerschmidt 의 방법(13)에 따라 측정하였으며, chlorogenic acid를 이용 하여 표준곡선을 작성하였으며 $\mathrm{mg} \%$ 로 나타내었다.

$\mathrm{DPPH}$ 라디칼 소거능은 Blois(14)의 방법으로 조사하였 다. 시료 $0.2 \mathrm{~mL}$ 와 $4 \times 10^{-4} \mathrm{M}$ a,a-diphenyl- $\beta$-picrylhydrazyl $(\mathrm{DPPH})$ 용액 $0.8 \mathrm{~mL}$ 을 가하여 10 초간 혼합하고 10 분간 방치한 후 $525 \mathrm{~nm}$ 에서 흡광도를 측정하여 아래와 같이 계산하였다.

$$
\text { DPPH radical scavenging activity }(\%)=\left(1-\frac{\mathrm{A}}{\mathrm{B}}\right) \times 100
$$

A : absorbance of DPPH solution with sample at $525 \mathrm{~nm}$

B : absorbance of DPPH solution without sample at $525 \mathrm{~nm}$

Table 1. Physical quality characteristics of peach fruits depending on the development stages

\begin{tabular}{|c|c|c|c|c|}
\hline & \multirow{2}{*}{ Sample } & \multicolumn{3}{|c|}{ Development stages } \\
\hline & & Stone hardening & Fruit enlargement & Ripening \\
\hline \multirow{3}{*}{$\begin{array}{l}\text { Length } \\
(\mathrm{mm})\end{array}$} & Wild Peach & $38.6 \pm 2.1^{1(\mathrm{c})(\mathrm{C} 3)}$ & $45.5 \pm 3.7^{\mathrm{bC}}$ & $53.4 \pm 4.3^{\mathrm{aC}}$ \\
\hline & Hikawa Hakuho & $47.0 \pm 3.7^{\mathrm{cB}}$ & $55.7 \pm 2.9^{\mathrm{bB}}$ & $60.8 \pm 1.8^{\mathrm{aB}}$ \\
\hline & Baekhyang & $53.1 \pm 2.3^{\mathrm{cA}}$ & $68.4 \pm 3.0^{\mathrm{bA}}$ & $88.6 \pm 5.3^{\mathrm{aA}}$ \\
\hline \multirow{3}{*}{$\begin{array}{l}\text { Width } \\
(\mathrm{mm})\end{array}$} & Wild Peach & $29.4 \pm 3.9^{\mathrm{cC}}$ & $43.2 \pm 4.5^{\mathrm{bC}}$ & $53.7 \pm 4.4^{\mathrm{aC}}$ \\
\hline & Hikawa Hakuho & $45.7 \pm 4.0^{\mathrm{cA}}$ & $63.6 \pm 3.2^{\mathrm{bB}}$ & $73.1 \pm 2.1^{\mathrm{aB}}$ \\
\hline & Baekhyang & $42.0 \pm 1.5^{\mathrm{cB}}$ & $68.5 \pm 3.1^{\mathrm{bA}}$ & $87.0 \pm 5.6^{\mathrm{aA}}$ \\
\hline \multirow{3}{*}{$\begin{array}{l}\text { Weight } \\
\text { (g) }\end{array}$} & Wild Peach & $18.2 \pm 3.7^{\mathrm{cB}}$ & $49.2 \pm 12.2^{\mathrm{bC}}$ & $84.2 \pm 19.6^{\mathrm{aC}}$ \\
\hline & Hikawa Hakuho & $61.4 \pm 12.9^{\mathrm{cA}}$ & $139.1 \pm 18.0^{\mathrm{bB}}$ & $193.1 \pm 12.7^{\mathrm{aB}}$ \\
\hline & Baekhyang & $56.9 \pm 5.5^{\mathrm{cA}}$ & $178.3 \pm 14.9^{\mathrm{bA}}$ & $337.9 \pm 71.0^{\mathrm{aA}}$ \\
\hline \multirow{3}{*}{ Ratio of length/width } & Wild Peach & $1.33 \pm 0.10^{\mathrm{aA}}$ & $1.06 \pm 0.06^{\mathrm{bA}}$ & $1.00 \pm 0.04^{\mathrm{cB}}$ \\
\hline & Hikawa Hakuho & $1.03 \pm 0.05^{\mathrm{aC}}$ & $0.88 \pm 0.04^{\mathrm{bC}}$ & $0.83 \pm 0.02^{\mathrm{CC}}$ \\
\hline & Baekhyang & $1.27 \pm 0.04^{\mathrm{aB}}$ & $1.00 \pm 0.06^{\mathrm{bB}}$ & $1.02 \pm 0.03^{\mathrm{bA}}$ \\
\hline
\end{tabular}

\footnotetext{
${ }^{1)}$ Value represent means \pm SD ( $\mathrm{n}=20$ )

${ }^{2) a-c}$ Means followed by the same letters within the row are not significantly different $(p<0.05)$.

${ }^{3) A-C}$ Means followed by the same letters within the column are not significantly different $(\mathrm{p}<0.05)$.
} 


\section{통계 처리}

모든 실험은 3회 반복 실시하여, 측정치를 평균과 표준편 차로 나타내었다. Statistical analysis system(SAS)(9.4, SAS Institute Inc., Cary, NC, USA)을 사용하여 Duncan의 다중검 정법에 따라 유의차 검정을 하였다 $(\mathrm{p}<0.05)$.

\section{결과 및 고찰}

\section{성숙 시기별 이화학적 품질 특성}

복숭아 과일의 성숙 시기별 과경, 과폭, 과중 및 과경/과 폭의 비를 조사한 결과는 Table 1 과 같다. 과경과 과폭, 과중은 모든 품종에서 숙기가 지날수록 증가하는 것을 알 수 있었다. 특히 성숙기에서 품종별로 과경과 과폭, 과중에 서 백향, 일천백봉, 돌복숭아 순으로 높았다 $(\mathrm{p}<0.05)$. 과경/ 과폭의 비의 경우 돌복숭아와 일천백봉에서는 숙기가 지날 수록 감소하는 경향을 보였으며, 백향은 과실비대기까지 감소하였으나, 성숙기와는 차이가 없었다. 성숙기에서의 과경/과폭의 비는 백향이 가장 컸으며, 일천백봉이 0.83 으 로 성숙이 진행될수록 과경보다 과폭의 성장이 더 큰 것을 알 수 있었다.

복숭아 과일의 성숙 시기별 경도를 조사한 결과는 Fig. 1 과 같다. 숙기가 진행됨에 따라 일천백봉의 경도는 4,838 $\mathrm{g} / \mathrm{cm}^{2}$ 에서 $250 \mathrm{~g} / \mathrm{cm}^{2}$ 으로, 백향의 경도는 $5,098 \mathrm{~g} / \mathrm{cm}^{2}$ 에서 $1,394 \mathrm{~g} / \mathrm{cm}^{2}$ 로 감소함을 볼 수 있었다. 반면 돌복숭아의 경우 경도가 숙기가 진행됨에도 불구하고 경도(3,378-3,730 $\left.\mathrm{g} / \mathrm{cm}^{2}\right)$ 의 차이를 보이지 않았다. 복숭아와 같은 핵과류인 매실도 마찬가지로 성숙함에 따라 경도가 감소함을 보였다 (15).

복숭아 과일의 성숙 시기별 당도와 산도를 조사한 결과 는 Table 2 와 같다. 당도의 경우 복숭아 모든 품종에서 경핵 기보다 과실비대기에서 증가하였으며, 과실비대기와 성숙 기는 유의적인 차이를 나타내지 않았다. 경핵기에서의 당 도는 돌복숭아가 가장 낮았고, 과실비대기에서는 백향이

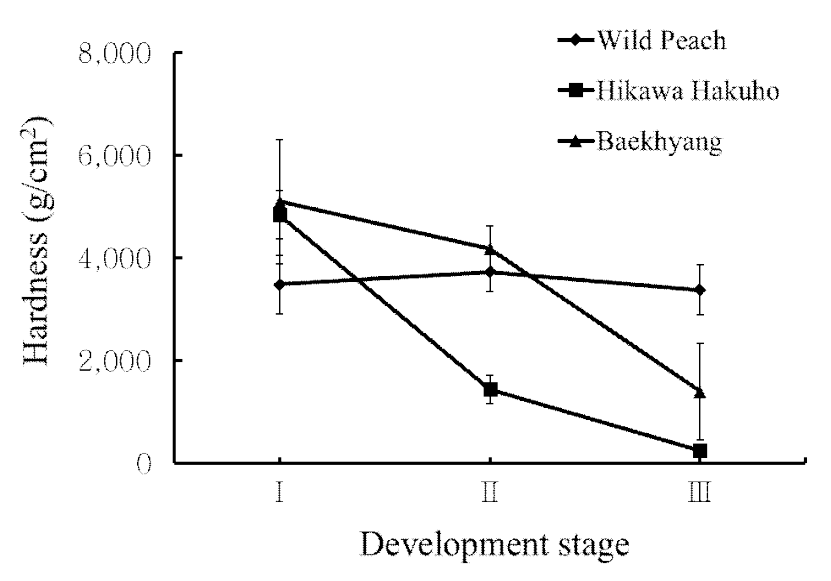

Fig. 1. Hardness of peach fruits depending on the development stages.

I , stone harding stage; II, fruit enlargement stage; III, ripening stage.

가장 높은 값을 나타냈다. 성숙기에서의 품종별로 당도는 유의적인 차이를 보이지 않았다. 이는 복숭아 과일의 성숙 시기에 따른 당도를 측정한 Cascales 등(16)의 연구와 비슷 한 경향을 나타내었다. 복숭아 과일의 산도는 일천백봉과 백향에서 숙기가 진행될수록 감소하였다. 모든 시기에서 일천백봉이 가장 낮은 산도를 나타냈으며, 경핵기를 제외 한 모든 시기에서 돌복숭아가 가장 높은 산도를 보였다. 이는 자두의 성숙에 따라 산도가 감소하며, 가용성 고형분 함량은 반대로 증가한다는 보고(17)와 유사하였다.

복숭아 과일의 성숙 시기별 당도/산도의 비(당산비)를 나타낸 결과는 Fig. 2와 같다. 경핵기에서는 품종별로 당산 비가 큰 차이를 보이지 않았다. 성숙에 따라 복숭아 과일의 당산비는 증가하였으며, 특히 일천백봉이 돌복숭아와 백향 에 비해 큰 폭으로 증가하였다. 이는 성숙 시기에 따라 당도 는 품종별로 비슷하지만 일천백봉의 산도가 다름 품종 보다 낮기 때문이다.

Table 2. Soluble solid contents and titratable acidity of peach fruits depending on the development stages

\begin{tabular}{|c|c|c|c|c|}
\hline & \multirow{2}{*}{ Sample } & \multicolumn{3}{|c|}{ Development stages } \\
\hline & & Stone hardening & Fruit enlargement & Ripening \\
\hline \multirow{3}{*}{$\begin{array}{c}\text { Sugar } \\
\left({ }^{\circ} \text { Brix }\right)\end{array}$} & Wild Peach & $8.4 \pm 0.3^{1 \mathrm{lb2} / \mathrm{B} 3)}$ & $10.4 \pm 0.1^{\mathrm{aB}}$ & $11.3 \pm 0.8^{\mathrm{aA}}$ \\
\hline & Hikawa Hakuho & $9.5 \pm 0.3^{\mathrm{bA}}$ & $10.8 \pm 0.5^{\mathrm{aB}}$ & $11.6 \pm 0.9^{\mathrm{aA}}$ \\
\hline & Baekhyang & $9.9 \pm 0.7^{\mathrm{bA}}$ & $12.0 \pm 0.3^{\mathrm{aA}}$ & $11.6 \pm 0.5^{\mathrm{aA}}$ \\
\hline \multirow{3}{*}{$\begin{array}{c}\text { Acidity } \\
(\%)\end{array}$} & Wild Peach & $0.9 \pm 0.0^{\mathrm{bA}}$ & $1.1 \pm 0.0^{\mathrm{aA}}$ & $0.5 \pm 0.0^{\mathrm{cA}}$ \\
\hline & Hikawa Hakuho & $0.8 \pm 0.0^{\mathrm{aB}}$ & $0.3 \pm 0.1^{\mathrm{bC}}$ & $0.2 \pm 0.0^{\mathrm{bC}}$ \\
\hline & Baekhyang & $1.0 \pm 0.0^{\mathrm{aA}}$ & $0.8 \pm 0.0^{\mathrm{bB}}$ & $0.4 \pm 0.1^{\mathrm{cB}}$ \\
\hline
\end{tabular}

\footnotetext{
${ }^{1)}$ Value represent means \pm SD $(\mathrm{n}=3)$.

2)a-c Means followed by the same letters within the row are not significantly different $(p<0.05)$

${ }^{3) A-C}$ means followed by the same letters within the column are not significantly different $(\mathrm{p}<0.05)$.
} 


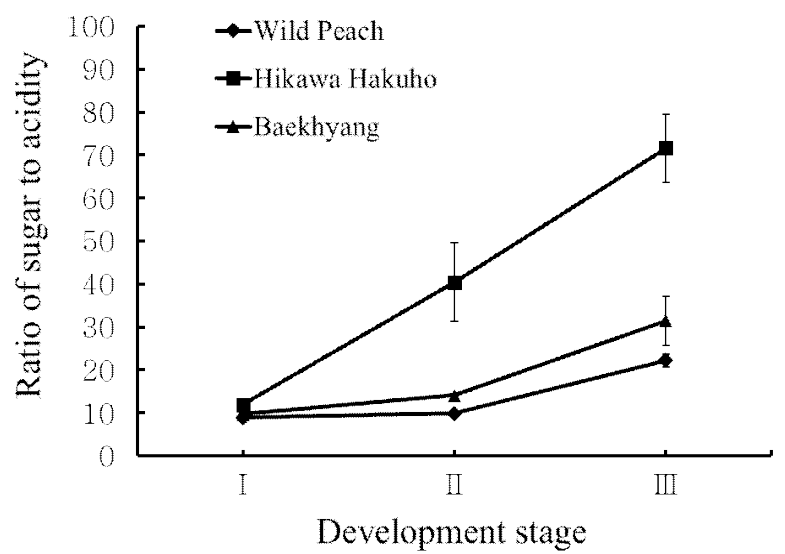

Fig. 2. Ratio of soluble solids to acidity of peach fruits depending on the development stages.

I , stone harding stage; II, fruit enlargement stage; III, ripening stage.

\section{성숙 시기별 항산화능}

복숭아 과일을 성숙 시기별로 총페놀 함량과 DPPH 라디 칼 소거능을 측정하여 항산화능을 조사한 결과는 Table 3과 같다. 식물의 2차 대사산물로서 phenolic acid, flavonoid, anthocyanin, condensed tannin과 같은 다양한 구조의 화합 물을 폴리페놀 화합물이라고 하며, 유리 라디칼 소거와 금 속 이온을 포착하는 반응에 직접 참여하는 항산화 활성을 비롯하여(18), 콜레스테롤 저하작용, 정장작용, 항암 및 항 산화 작용 등과 같은 다양한 기능성이 보고되고 있다(19). 복숭아 과일에 존재하는 폴리페놀 화합물의 종류로는 neochlorogenic acid, chlorogenic acid, catechin, quercetin-3O-galactoside 등이 있다(20).

복숭아 과일의 성숙 시기별 총페놀 함량은 모든 품종에 서 경핵기보다 성숙기의 총페놀 함량이 크게 감소한 것을 볼 수 있었다. 모든 시기에서 백향의 총페놀 함량이 돌복숭 아와 일천백봉보다 높았다. 경핵기에서는 일천백봉이 가장 낮은 총페놀 함량을 보였으나, 과실비대기와 성숙기의 총
페놀 함량은 품종 간에 유의적인 차이를 보이지 않았다. 복숭아 과일의 성숙 시기별 DPPH 라디칼 소거능은 총페 놀 함량과 유사하게 모든 품종에서 경핵기에 비해 성숙기에 서 감소하였다. 또한 모든 시기에서 백향의 DPPH 라디칼 소거능이 돌복숭아와 일천백봉에 비해 높았다. 돌복숭아가 일천백봉에 비해 경핵기와 과실비대기에서 높은 라디칼 소거능을 보였으나, 성숙기에서는 유의적인 차이가 없었 다. 복숭아 과일의 총페놀 함량과 DPPH 라디칼 소거능의 상관계수는 $0.7083(\mathrm{p}<0.0001)$ 으로, 다소 상관성이 있었으 며, 품종별로 성숙도에 따라 항산화 활성과 항산화성분을 조사한 Jung 등(11)의 연구결과와 유사하였다.

\section{요 약}

본 연구는 복숭아 과일의 이용성을 증대할 목적으로, 품 종별로 복숭아 과일의 성숙 단계에 있어서 이화학적 품질 특성과 항산화능을 조사하였다. 물리적 특성은 과일의 과 경, 과폭, 과중 및 경도를 측정하였으며, 화학적 특성은 총산 도, 당도를 측정하였고, 항산화능으로 총페놀 함량과 $\mathrm{DPPH}$ 라디칼 소거 활성을 측정하였다. 복숭아 과일의 품종별 과 경, 과폭, 과중은 숙기가 진행됨에 따라 점점 증가하였으며 과경의 경우 돌복숭아가 가장 작았고, 백향이 가장 컸다. 과폭과 과중에 있어서 경핵기의 경우 돌복숭아가 가장 작았 고 일천백봉이 가장 컸으나, 과실비대기와 성숙기에서는 백향, 일천백봉, 돌복숭아 순으로 과중이 컸다. 과폭에 대한 과경의 비율은 성숙하면서 감소하는 경향을 보였다. 경도 는 일천백봉과 백향의 경우 숙기가 진행됨에 따라 현저하게 감소하였으나 돌복숭아의 경우는 숙기가 진행되어도 비슷 한 정도의 경도를 보였으며, 성숙기의 경도는 돌복숭아, 백향, 일천백봉 순으로 높았다. 복숭아 과일의 품종별 당도 는 경핵기에 가장 낮았으며, 성숙되면서 모든 품종이 증가 하는 경향을 보였다. 복숭아 과일의 산도는 반대로 감소하

Table 3. Antioxidant capacities of peach fruits depending on the development stages

\begin{tabular}{|c|c|c|c|c|}
\hline & \multirow{2}{*}{ Sample } & \multicolumn{3}{|c|}{ Development stages } \\
\hline & & Stone hardening & Fruit enlargement & Ripening \\
\hline \multirow{3}{*}{$\begin{array}{c}\mathrm{TPC}^{1)} \\
(\mathrm{mg} \%)\end{array}$} & Wild Peach & $20.7 \pm 0.4^{(2) \mathrm{a} 33 \mathrm{~B} 4)}$ & $13.9 \pm 0.3^{\mathrm{bB}}$ & $10.5 \pm 0.3^{\mathrm{cB}}$ \\
\hline & Hikawa Hakuho & $16.0 \pm 0.7^{\mathrm{aC}}$ & $11.3 \pm 1.0^{\mathrm{bB}}$ & $10.4 \pm 0.3^{\mathrm{bB}}$ \\
\hline & Baekhyang & $72.7 \pm 0.9^{\mathrm{aA}}$ & $66.4 \pm 2.1^{\mathrm{bA}}$ & $32.5 \pm 1.4^{\mathrm{cA}}$ \\
\hline \multirow{3}{*}{$\begin{array}{c}\mathrm{DPPH} \\
(\%)\end{array}$} & Wild Peach & $84.4 \pm 0.9^{\mathrm{aB}}$ & $82.9 \pm 2.4^{\mathrm{aB}}$ & $42.3 \pm 3.9^{\mathrm{bB}}$ \\
\hline & Hikawa Hakuho & $69.2 \pm 0.5^{\mathrm{aC}}$ & $60.5 \pm 2.4^{\mathrm{bC}}$ & $41.6 \pm 7.1^{\mathrm{cB}}$ \\
\hline & Baekhyang & $92.6 \pm 1.1^{\mathrm{aA}}$ & $91.6 \pm 0.1^{\mathrm{aA}}$ & $80.9 \pm 1.0^{\mathrm{bA}}$ \\
\hline
\end{tabular}

\footnotetext{
${ }^{1)}$ TPC, total phenolic contents; DPPH, DPPH radical scavenging activity.

${ }^{2)}$ Value represent means $\pm \mathrm{SD}(\mathrm{n}=3)$.

${ }^{33-c}$ Means followed by the same letters within the row are not significantly different $(p<0.05)$.

${ }^{4) A-C}$ Means followed by the same letters within the column are not significantly different $(\mathrm{p}<0.05)$.
} 
여, 당산비가 증가하는 경향을 보였으며, 성숙기의 일천백 봉이 현저히 당산비가 높았다. 총페놀 함량은 경핵기의 백 향이 가장 높았고, 성숙함에 따라 총페놀 함량이 감소하였 다. DPPH 라디칼 소거능은 경핵기에서 돌복숭아가 가장 높았으며, 과실비대기와 성숙기에서는 품종별로 유의적인 차이가 없었다. 복숭아 과일은 성숙함에 따라 과경, 과폭, 과중은 증가하며, 경도가 감소하여, 당산비가 증가하였으 며 항산화능은 감소하였다 $(\mathrm{p}<0.05)$.

\section{References}

1. Jung GH, Lee JH, Chun MH, Park WH (2016) Changes in peach consumption trends and response strategies. Gyeonggi Provincial Agricultural Research \& Extension Services, Hwaseong, Korea, p 8

2. Lee HB, Yang CB, Yu TJ (1972) Studies on the chemical composition of some fruit vegetables and fruits in Korea (I)-On the free amino acid and sugar contents in tomato, watermelon, muskmelon, peach and plum. Korean J Food Sci Technol, 4, 36-43

3. Lee DS, Woo SK, Yang CB (1972) Studies on the chemical composition of major fruits in Korea-On non-volatile organic acid and sugar contents of apricot (maesil), peach, grape, apple and pear and its seasonal variation. Korean J Food Sci Technol, 4, 134-139

4. Park YG, Choi IU, Kim HM, Kim SR, Park MW, Cha HS, Choi HD, Suk HM, Kang YH (1999) Studies on the utilization of unripe apples. Final report of MAF, MAF GA0108-9910, p 23-47

5. Lee JB, Chung HS (2008) Studies on the components of unripe peaches. Korean J Food Preserv, 15, 79-83

6. Globerman H, Navok T, Chevion M (1984) Haemolysis in a G6PD-deficient child induced by eating unripe peaches. Eur J Haematol, 33, 337-341

7. Kim HJ (2007) Isolation and characterization of active whitening compound from Prunus persica. MS Thesis. Korea University, Korea, p 31-35

8. Lee SK, Oh A, Shin SH, Kim HN, Kang WW, Chung SK (2017) Amygdalin contents in peaches at different fruit development stages. Prev Nutr Food Sci, 22, 237-240
9. Pressey R, Hinton DM, Avants JK (1971) Development of polygalacturonase activity and solubilization of pectin in peaches during ripening. J Food Sci, 36, 1070-1073

10. McCready RM, McComb EA (1954) Pectic constituents in ripe and unripe fruit. J Food Sci, 19, 530-535

11. Jung KM, Kim SY, Lee SH (2017) In vitro correlation and analysis of anti-oxidant and anti-inflammatory activities by fruit ripening of peach cultivars. Korean J Food Preserv, 24, 638-646

12. Chun MS, Lee TS, Noh BS (1995) The changes in organic acid and fatty acids in kochujang prepared with different mashing methods. Korean J Food Sci Technol, 27, 25-29

13. Hammerschmidt PA, Pratt DE (1978) Phenolic antioxidants of dried soybeans. J Food Sci, 43, 556-559

14. Blois MS (1958) Antioxidant determinations by the use of a stable free radical. Nature, 181, 1199-1200

15. Cha HS, Park YK, Park JS, Park MW, Jo JS (1999) Changes in firmness, mineral composition and pectic substances of mume (Prunus mume Sieb. et Zucc) fruits during maturation. Korean J Food Presev, 6, 488-494

16. Cascales AI, Costell E, Romojaro F (2005) Effects of the degree of maturity on the chemical composition, physical characteristics and sensory attributes of peach (Prunus persica) cv. Caterin. Food Sci Technol Int, 11, 345-352

17. Heo JW, Yun SJ, Park SM (2016) Variation of major fruit characteristics during fruit development period in plum cultivars. Agriculture Life Science, 50, 13-24

18. Kim MJ, Park EJ (2011) Feature analysis of different in vitro antioxidant capacity assays and their application to fruit and vegetable samples. J Korean Soc Food Sci Nutr, 40, 1053-1062

19. Choi SY, Cho HS, Sung NJ (2006) The antioxidative and nitrite scavenging ability of solvent extracts from wild grape (Vitis coignetiea) skin. J Korean Soc Food Sci Nutr, 35, 961-966

20. Zhao X, Zhang W, Yin X, Su M, Sun C, Li X, Chen K (2015) Phenolic composition and antioxidant properties of different peach [Prunus persica (L.) Batsch] cultivars in China. Int J Mol Sci, 16, 5762-5778 